\title{
Adsorption and kinetic/thermodynamic characterization of aluminium corrosion inhibition in sulphuric acid by extract of Alstonia boonei.
}

\author{
Ituen, E. B. $(*)^{\mathrm{a}}$, Udo, U. E. ${ }^{a}$ Odozi, N. W. ${ }^{b}$ and Dan, E. U. ${ }^{a}$ \\ A Corrosion and Electrochemical Laboratory, Department of Chemistry, Faculty of Science, University of Uyo, \\ Nigeria. \\ b Department of Chemistry, Faculty of Science, University of Ibadan, Nigeria.
}

\begin{abstract}
Investigation of adsorptive and inhibitive effect of extracts of Alstonia boonei on aluminium corrosion in $1.0 \mathrm{M}$ sulphuric acid yielded inhibition efficiency of 59.6 and $47.7 \%$ for $0.5 \mathrm{~g} / \mathrm{L}$ concentration of the extracts at 303 and $333 \mathrm{~K}$ respectively for gravimetric measurement. Gasometric measurement gave an inhibition efficiency of 61.0 and $49.9 \%$ at 303 and $333 \mathrm{~K}$ respectively. Adsorption behavior was best approximated by the Freundlich adsorption model with evidence of efficient adsorbate-adsorbent binding potential $\left(K_{\text {ads }}\right)$. Physical adsorption mechanism is proposed from the trend of $\Delta G_{\text {ads }}$ obtained. The adsorption of the extracts onto the metal surface was spontaneous and exothermic. The extracts increased the energy barrier (Ea) of the inhibited solution above that of the blank and hence the inhibition process. A decrease in entropy resulting in formation of ordered adsorbed layer speculated from deductions on transition state plots.
\end{abstract}

Keywords: A. boonei extract, inhibition efficiency, inhibitor, physisorption.

\section{Introduction}

Extracts of many plants have been investigated and reported by several authors as having the potentiality to inhibit metal dissolution in various aggressive media attributed to the type of organic compounds that constitute their phytochemistry [1]. The environmental friendliness (green) of plants extracts has extended its application frontiers even to the oil and gas industries and hence its popularity and acceptability, making corrosion inhibition studies on the use of plants extracts a very active field. Alstonia boonei De wild belongs to the family Apocynaceae [common names: pattern wood/stool wood/chineese wood (English), egbu (Igbo), ukpo (Efik/Ibibio) and awum (Yoruba)] and provides firewood and timber, the stem exudes latex which is dangerous to the eye. Initial analysis of the extract revealed echitamine (main alkaloid), Na-formylechitamidine and a lactone boonein. It also contains $\beta$-amyrin (a triterpenoid) and lupeol, urosolic acid, loganin [2]. Extracts of $A$. boonei is rich in alkaloids, tannins, saponins, flavonoids, cardiac glycosides, ascorbic acid, and phenolics which are associated with its antioxidant properties [3]. The alkaloids are known to have diuretic, splasmolytic, hypotensive and nephrotoxic properties [4]. In the West African sub-regions, the leaves, roots, or stem of the plant has been extracted in various media and used as cure for veneral diseases, worms, rheumatic pains, asthma, and impotence [5]. Researchers have also reported that extracts of the plant exhibit antimalarial [6] and anti-inflammatory [7] properties. However, no report on the use of the extract as metals corrosion retarders/inhibitors is available in literature, hence the motivation of the authors for this study.

The chemical substances above present in extract of $A$. boonei contain hetero atoms namely $\mathrm{N}$ and $\mathrm{O}$ as well as aromatic rings and multiple bonds which are sources of electrons for donation to empty orbital of metals, a phenomenon responsible for the formation of a protective layer that blankets the metal surface and retards its rate of dissolution by an aqueous aggressive medium with which the metal is in contact. The mechanism of inhibition is usually by adsorption, which may involve weak interaction forces between charges ions (physisorption) or actual formation of bonds between the metal and the adsorbed layer (chemisorption) or both. In this work, the adsorptive and inhibitive property of ethanolic extract of A. boonei on aluminium in $1.0 \mathrm{M}$ $\mathrm{H}_{2} \mathrm{SO}_{4}$ is investigated and kinetic/thermodynamic parameters that describe the adsorption process are elucidated.

\section{Experimental}

2.1Materials: Mild steel sheets supplied by Sky Aluminium Limited, Uyo, Nigeria were mechanically press-cut into $4.0 \mathrm{~cm} \times 4.0 \mathrm{~cm}$ dimensions, degreased in absolute ethanol, rinsed in acetone, air-dried at room temperature and stored in a moisture free desiccator without further polishing. Sulphuric acid (1.0 M) was prepared in deionized water from $98 \%$ Analar grade reagent supplied by BDH, England.

2.2Preparation of A. boonei Extract: Samples of A. boonei (consisting of the leaves and stem) was collected from Ikot Ambon Ibesikpo, Akwa Ibom State, Nigeria, rinsed in distilled water, sun-dried and ground to powder 
using electric blender. The dry sample in the powdery form was extracted in hot absolute ethanol for 72 hours. The extract was concentrated in vacuum evaporator and to dryness with a steam bath to completely remove the ethanol. The appropriate masses were accurately weighed and respectively dissolved in $1.0 \mathrm{M} \mathrm{H}_{2} \mathrm{SO}_{4}$ to obtain the different concentrations $(0.1-0.5 \mathrm{~g} / \mathrm{L})$ used for the gravimetric and gasometric measurements.

2.3Gravimetric Measurements: Pre-weighed aluminium coupons were totally immersed in $250 \mathrm{~mL}$ beakers containing $1.0 \mathrm{M} \mathrm{H}_{2} \mathrm{SO}_{4}$ in the absence and presence of different concentrations of $A$. boonei extract and retrieved at $2 \mathrm{~h}$ intervals progressively for $10 \mathrm{~h}$. The retrieved coupons were cleaned and dried as reported elsewhere [8] and reweighed using FA2104A digital weighing balance (sensitivity $\pm 0.0001 \mathrm{~g}$ ). The difference in weights $a b$ initio and after immersion was recorded as weight loss. The tests were performed in triplicates to guarantee reliability and the averages $(\Delta w)$ were used to compute the corrosion rates $\left(\pi_{\mathrm{g}}\right)$, inhibition efficiencies $\left(\% \mu_{\mathrm{g}}\right)$ and degree of surface coverage $\left(\theta_{\mathrm{g}}\right)$ according to equations 1-3 below. The procedure was repeated at temperatures between 313,323

and $333 \mathrm{~K}$ maintained in a regulated thermostated bath.

$$
\begin{aligned}
& \pi_{\mathrm{g}}=\Delta \mathrm{w} / A T \\
& \mu_{\mathrm{g}}=100\left(\Delta w_{\mathrm{b}}-\Delta w_{\mathrm{i}}\right) / \Delta w_{\mathrm{b}} \\
& \theta_{\mathrm{g}}=0.01 \mu
\end{aligned}
$$

where $A\left(\mathrm{~cm}^{2}\right)$ is the cross sectional area of the aluminium coupon, $\Delta w_{\mathrm{b}}$ is the average/mean weight loss in the blank (free acid) solution, $\Delta w_{\mathrm{i}}$ is the average/mean weight loss in the presence of $A$. boonei extract, and $T$ is the total immersion time of $10 \mathrm{~h}$

2.4Gasometric Measurement: Acid attacks of the metal in the gasometric assembly resulted in the evolution of hydrogen gas, the volume of which was correlated with the corrosion rate $\left(\pi_{H}\right)$ and inhibition efficiency $\left(\mu_{H}\right)$ for each system according equation 4. Detailed description of procedure used has been reported elsewhere [9]. The progress of the corrosion process was monitored at fixed time interval in the different test solutions at $303-333$ K.

$$
\begin{aligned}
& \pi_{\mathrm{H}}=\left(V_{\mathrm{t}}-V_{0}\right) /\left(T_{\mathrm{t}}-T_{\mathrm{t}}\right) \\
& \mu_{\mathrm{H}}=100\left\{\pi_{\mathrm{H} \text { (blank) }}-\pi_{\mathrm{H} \text { (extract) }}\right\} / \pi_{\mathrm{H} \text { (blank) }}
\end{aligned}
$$

where $V_{t}$ and $V_{0}$ are the volumes of hydrogen evolved at time $T_{t}$ and $T_{0}$ respectively, $\pi_{H(b l a n k)}$ is the corrosion rate of the free acid solution and $\pi_{\mathrm{H}(\text { extract })}$ are the corrosion rate in the presence of the extract based on hydrogen evolution measurements.

\section{Results And Discussion}

3.1 Corrosion rate and Inhibition efficiency: The weight loss data obtained were used to compute corrosion rate. Corrosion rate increased with increase in temperature but showed marked decrease in the presence of the extracts: decreasing with increase in extract concentration. Inhibition efficiency increased with increase in concentration of the extract and decreased with increase in temperature. Table 1 shows the corrosion rates, inhibition efficiencies and degrees of surface coverage for the dissolution of aluminium in $1.0 \mathrm{M} \mathrm{H}_{2} \mathrm{SO}_{4}$ in the absence and presence of different concentrations of $A$. boonei extract at $303-333 \mathrm{~K}$ obtained using both gravimetric (a) and gasometric (b) techniques while figure 1 show the variation of inhibition efficiency with temperature of the systems for the different concentrations studied. The values obtained for the gravimetric and

\begin{tabular}{|c|c|c|c|c|c|c|c|c|c|c|c|}
\hline \multirow[t]{2}{*}{ Systems } & \multicolumn{4}{|c|}{$\pi_{\mathrm{g}}\left(\mathrm{mg} / \mathrm{cm}^{-2} / \mathrm{h}^{-1}\right)$} & \multicolumn{4}{|c|}{$\mu_{g}(\%)$} & \multicolumn{3}{|c|}{$\theta_{g}$} \\
\hline & 303 & 313 & 323 & 333 & 303 & 313 & 323 & 333 & 303 & 313 & 323 \\
\hline 333 & & & & & & & & & & & \\
\hline Blank & 5.12 & 10.98 & 13.11 & 16.02 & - & - & - & - & - & - & - \\
\hline $\begin{array}{ll}0.1 \mathrm{~g} / \mathrm{L} \text { extract } \\
0.38\end{array}$ & 2.68 & 6.57 & 7.85 & 9.99 & 47.6 & 44.0 & 40.1 & 37.6 & 0.48 & 0.44 & 0.40 \\
\hline $\begin{array}{ll}0.2 \mathrm{~g} / \mathrm{L} \text { extract } \\
0.41\end{array}$ & 2.55 & 5.79 & 7.45 & 9.52 & 50.1 & 47.3 & 43.1 & 40.6 & 0.50 & 0.47 & 0.43 \\
\hline $\begin{array}{l}0.5 \mathrm{~g} / \mathrm{L} \text { extract } \\
0.48\end{array}$ & 2.07 & 4.84 & 6.38 & 8.21 & 59.6 & 55.9 & 50.4 & 47.7 & 0.60 & 0.56 & 0.54 \\
\hline
\end{tabular}
gasometric measurements were comparable and in good agreement.

Table 1: (a) Calculated values of Corrosion rate, Inhibition efficiency and Degree of surface coverage data for the retardation of aluminium dissolution in $1.0 \mathrm{M} \mathrm{H}_{2} \mathrm{SO}_{4}$ in the absence and presence of different concentrations of A. boonei extract at 303 - $333 \mathrm{~K}$ using gravimetric technique 
Table 1: (b) Calculated values of Corrosion rate, Inhibition efficiency and degree of surface coverage data for the retardation of aluminium dissolution in $1.0 \mathrm{M} \mathrm{H}_{2} \mathrm{SO}_{4}$ in the absence and presence of different concentrations of $A$. boonei extract at $303-333 \mathrm{~K}$ using gasometric technique

\begin{tabular}{|c|c|c|c|c|c|c|c|c|c|c|c|}
\hline \multirow[t]{2}{*}{ Systems } & \multicolumn{4}{|c|}{$\pi_{\mathrm{H}}\left(\mathrm{mg} / \mathrm{cm}^{-2} / \mathrm{h}^{-1}\right)$} & \multicolumn{4}{|c|}{$\mu_{H}(\%)$} & \multicolumn{3}{|c|}{$\theta_{\mathrm{H}}$} \\
\hline & 303 & 313 & 323 & 333 & 303 & 313 & 323 & 333 & 303 & 313 & 323 \\
\hline $\begin{array}{l}333 \\
\text { Blank }\end{array}$ & & & & & & & & & & & \\
\hline $\begin{array}{l}\text { Blank } \\
-\end{array}$ & 5.12 & 10.97 & 13.10 & 16.01 & - & - & - & - & - & - & - \\
\hline $\begin{array}{ll}0.3 \mathrm{~g} / \mathrm{L} \text { extract } \\
0.40\end{array}$ & 2.57 & 5.91 & 7.49 & 9.76 & 49.7 & 46.2 & 42.9 & 39.9 & 0.50 & 0.46 & 0.43 \\
\hline $\begin{array}{l}0.4 \mathrm{~g} / \mathrm{L} \text { extract } \\
0.41\end{array}$ & 2.45 & 5.53 & 7.16 & 9.39 & 52.1 & 49.7 & 45.4 & 41.4 & 0.52 & 0.50 & 0.45 \\
\hline $\begin{array}{l}0.5 \mathrm{~g} / \mathrm{L} \text { extract } \\
0.50\end{array}$ & 2.00 & 4.57 & 6.09 & 8.01 & 61.0 & 58.3 & 53.6 & 49.9 & 0.61 & 0.58 & 0.54 \\
\hline
\end{tabular}

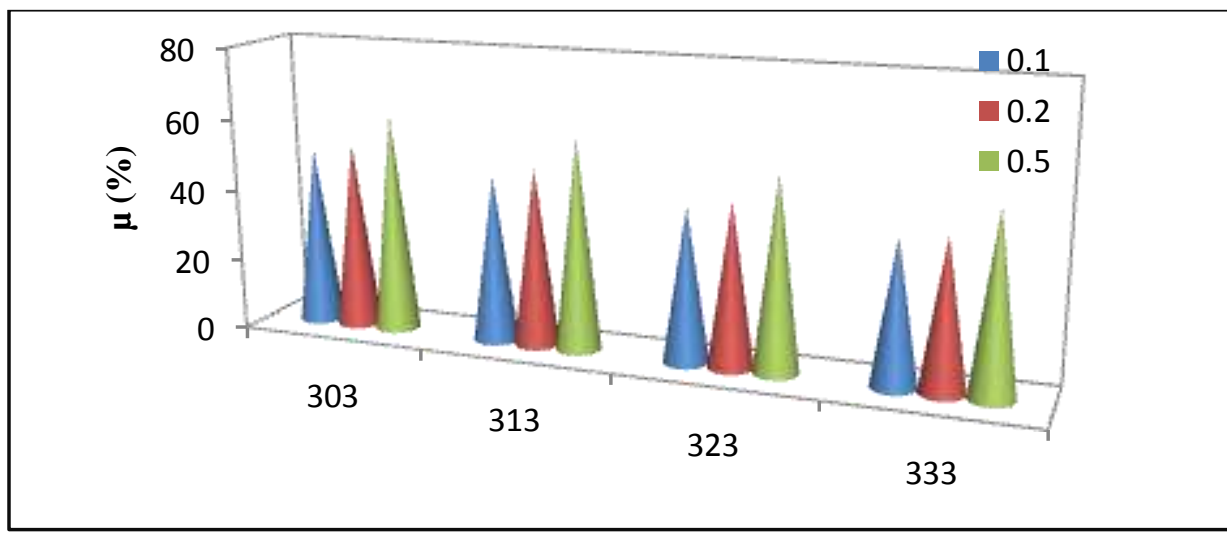

$T(K)$

Figure 1 (a): variation of inhibition efficiency with temperature for the retardation of aluminium dissolution in $1.0 \mathrm{M} \mathrm{H}_{2} \mathrm{SO}_{4}$ in the absence and presence of different concentrations of A. boonei extract at $303-333 \mathrm{~K}$ using gravimetric technique.

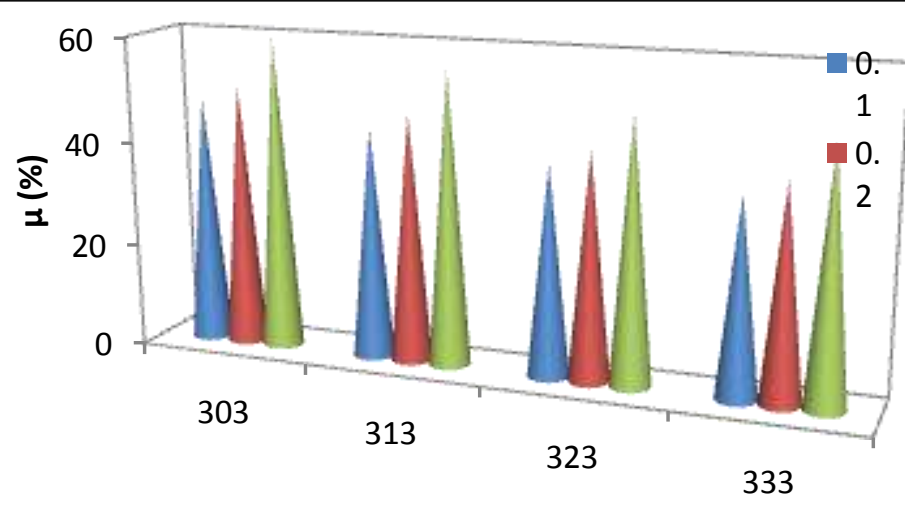

$\mathrm{T}(\mathrm{K})$

Figure 1 (b): variation of inhibition efficiency with temperature for the retardation of aluminium dissolution in 1.0 $\mathrm{M} \mathrm{H}_{2} \mathrm{SO}_{4}$ in the absence and presence of different concentrations of A. boonei extract at $303-333 \mathrm{~K}$ using gasometric technique. 
The decrease in inhibition efficiency with increase in temperature suggests possible desorption of the active adsorbed species in the extract from the metal surface as temperature rises and this trend has been associated with physical adsorption [10]. The extract probably inhibits the metal corrosion by physical adsorption of the phytochemical constituents (i.e. alkaloids, saponins, lactone, tannins, organic acid, terpenoids, etc) onto the metal surface. The different constituents form weak surface organometallic [Al-Inh] complexes with the aluminium in several orders of strengths which is difficult to characterize due to the unknown quantity and complexity of the probably charged phytochemical constituents.

3.2 Adsorption and thermodynamic Characterization: Adsorption isotherms are usually employed to explain the mechanism of interaction between an inhibitor (adsorbate) and an adsorbent surface. This is usually achieved by fitting the degree of surface coverage data into various adsorption isotherms or models and the correlation coefficients (highest) used to determine the best fit isotherm which can then be used to describe the inhibitor adsorption mechanism. In this work, the best fitted isotherm was the Freundlich adsorption model which relates the degree of surface coverage to the concentration of the extracts according to equation 6-7 below:

$$
\theta=\mathrm{K}_{a d s} \mathrm{C}^{\mathrm{n}}
$$

also written as

$$
\log \theta=\log \mathrm{K}_{a d s}+n \log C
$$

where $\mathrm{K}_{a d s}$ is the equilibrium constant of adsorption-desorption process and is related to the standard Gibbs free energy change of adsorption-desorption process $\Delta \mathrm{G}_{a d s}$ (equation 8)

$$
K_{a d s}=0.018 \exp \left(-\Delta G^{*}{ }_{a d s} / R T\right)
$$

where $\mathrm{R}$ is the universal gas constant and $\mathrm{T}$ is the absolute temperature.

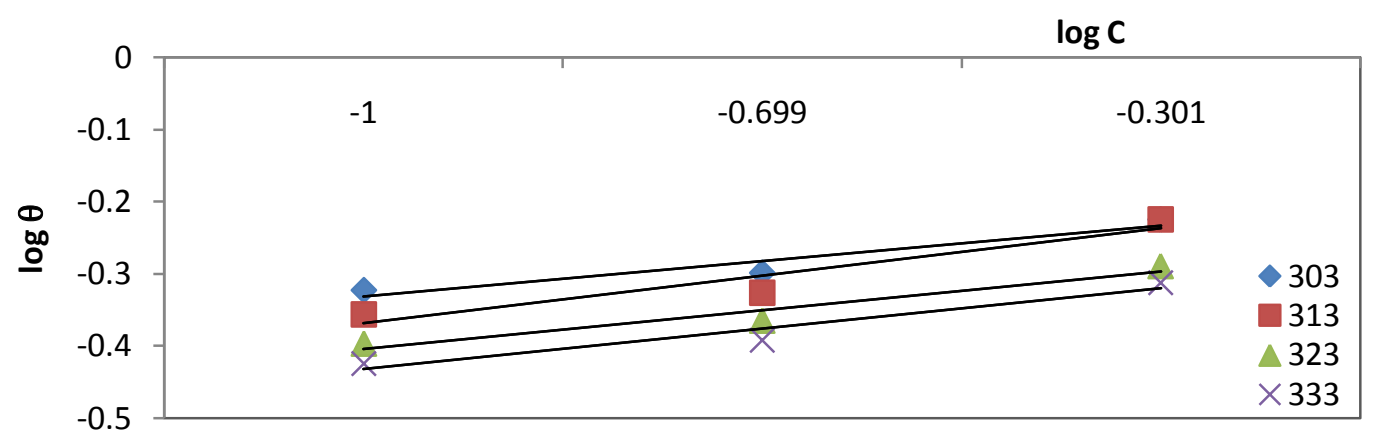

Figure 2 (a): Freundlich adsorption isotherm for the retardation of aluminium dissolution in $1.0 \mathrm{M} \mathrm{H}_{2} \mathrm{SO}_{4}$ using gravimetric technique.

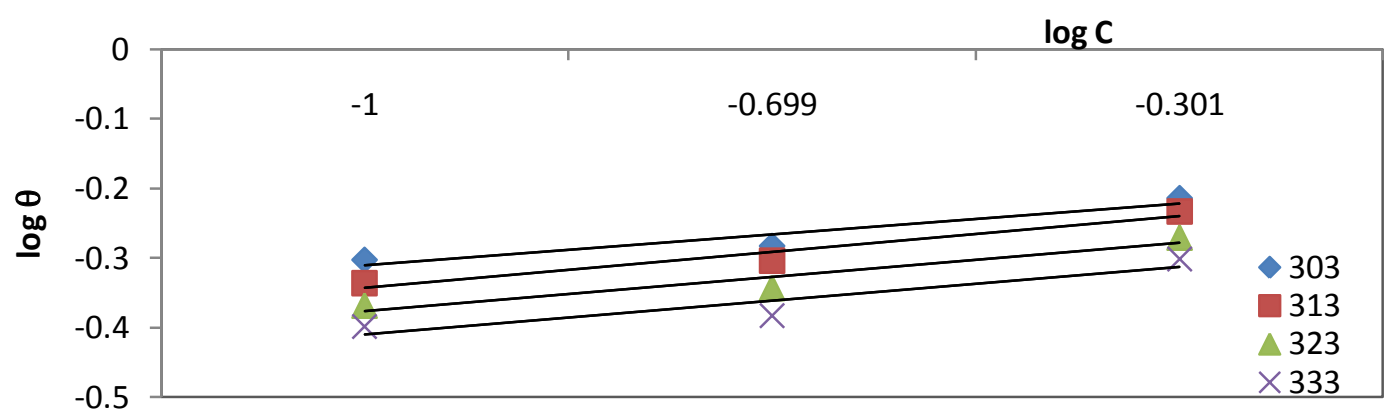

Figure 2 (b): Freundlich adsorption isotherm for the retardation of aluminium dissolution in $1.0 \mathrm{M} \mathrm{H}_{2} \mathrm{SO}_{4}$ using gasometric technique.

A plot of $\log \theta$ against $\log \mathrm{C}$ (figure 2) yields linear curves with slopes equal to $n$ : $0<n<1$ and intercepts equal to $\log \mathrm{K}_{a d s}$ and the adsorption parameters (i.e $\mathrm{K}_{a d s}, \mathrm{n}$ and $\Delta G_{a d s}$ ) deduced are shown in table 2. The fractional values of $n$ show great adherence to the adsorption model and the large values of $\mathrm{K}_{a d s}$ suggest efficient binding potential of the inhibitor onto the metal surface [11]. The decrease in magnitudes of $\mathrm{K}_{a d s}$ with increase in temperature observed is of striking significance and may be explained: an increase in temperature elicits a domino effect of desorption of some adsorbed components of the A. boonei extracts from the metal surface. This observation is consistent with physical adsorption mechanism earlier proposed. 
Adsorption and kinetic/thermodynamic characterization of aluminium corrosion inhibition in

Table 2: Adsorption parameters computed from the Freundlich Adsorption Isotherm

\begin{tabular}{llccc}
\hline Technique & $\mathrm{T}(\mathrm{K})$ & $\mathrm{n}$ & $\mathrm{K}_{a d s}$ & $\Delta G_{a d s}$ \\
\hline \multirow{3}{*}{ Gravimetric } & 303 & 0.049 & 0.417 & -27.8 \\
& 313 & 0.065 & 0.369 & -32.8 \\
& 323 & 0.054 & 0.348 & -35.8 \\
\multirow{3}{*}{ Gasometric } & 333 & 0.056 & 0.325 & -39.3 \\
& 303 & 0.044 & 0.442 & -26.0 \\
& 313 & 0.051 & 0.405 & -29.7 \\
& 323 & 0.048 & 0.377 & -33.1 \\
\hline
\end{tabular}

It has also been established that values of $\Delta \mathrm{G}_{a d s}$ up to $-20 \mathrm{~kJ} / \mathrm{mol}$ is suggests electrostatic interaction between charged species in the adsorbent-adsorbate interface (i.e. physical adsorption) while those more negative than $40 \mathrm{~kJ} / \mathrm{mol}$ suggests charge transfer or sharing from or between the inhibitor and the metal surface (i.e. chemical adsorption) in which, most often, a coordinate type of bond forms. The values of $\Delta G_{a d s}$ computed and shown in table 2 also support the physical adsorption mechanism. The negative values of $\Delta G_{a d s}$ indicate that the adsorption of the extracts is spontaneous.

Gibbs free energy change correlates with other thermodynamic parameters in line with the basic thermodynamic equation (equation 9) and the Van't Hoff equation (equation 9), hence the enthalpies (heat, $\Delta H_{a d s}$ ) of adsorption are estimated graphically from $\ln \mathrm{K}_{a d s}$ vs $1 / \mathrm{T}$ plot (figure 3) and the corresponding entropies of adsorption $\left(\Delta S_{a d s}\right)$ calculated (table 3$)$.

$$
\begin{aligned}
& \ln \mathrm{K}_{a d s}=-\Delta \mathrm{H}_{a d s} / \mathrm{RT}+\text { constant } \\
& \Delta S_{a d s}=\left(\Delta H_{a d s}-\Delta G_{a d s}\right) / \mathrm{T}
\end{aligned}
$$

The negative values of $\Delta H_{a d s}$ and obtained imply that the adsorption process is exothermic in nature. Bond enthalpies are independent of the compound in which they appear and quantitatively denote physisorption if $\Delta H_{a d s}<0$ (i.e exothermicity, usually associated with formation of new bonds and evolution of heat). On the other hand, chemisorptions (bond breaking energies, usually involving absorption of heat) may be inferred if $\Delta H_{a d s}>0$. The empirical values $\Delta H_{a d s}$ obtained are less than zero, indicating the formation of a covalent type of bond in the physisorbed layer and the evolution of energy. Adsorption processes with $\Delta \mathrm{S}_{a d s}<0$, as obtained here, are better described in terms of orderliness of the active species in the aggressive aqueous medium. Prior to adsorption, active ingredients of the extracts are assumed to be more disordered (chaotic) in the bulk medium but as the adsorption onto the metal surface progresses, orderliness gradually sets in leading to a decrease in entropy. The number of active molecules present in the bulk solution may have also decreased occasioned by involvement of much of the other molecules in the adsorption process, and hence the decrease in entropy.

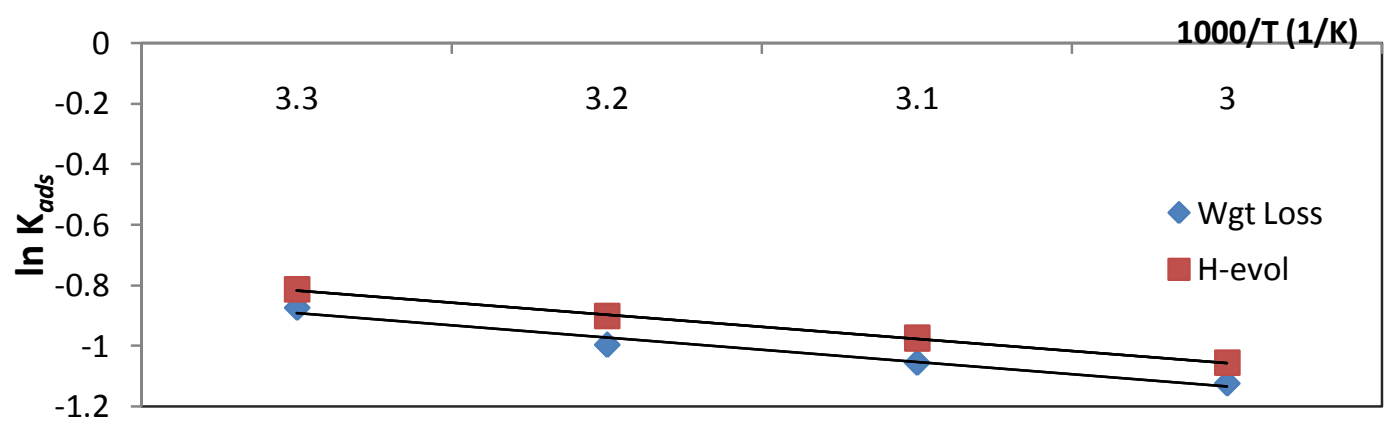

Figure 3: Van't Hoff's plot of In Kads against 1/T for the adsorption of extracts of A. boonei onto aluminium.

Table 3: Adsorption parameters from Van't Hoff's plot for the adsorption of extracts of A. boonei onto

\begin{tabular}{|c|c|c|c|c|}
\hline Technique & $\mathrm{T}(\mathrm{K})$ & $\Delta G_{a d s}$ & $\Delta H_{a d s}$ & $\Delta S_{a d s}$ \\
\hline & 303 & -27.8 & -15.13 & -0.042 \\
\hline \multirow{4}{*}{ Gravimetric } & 313 & -32.8 & -15.13 & -0.056 \\
\hline & 323 & -35.8 & -15.13 & -0.064 \\
\hline & 333 & -39.3 & -15.13 & -0.073 \\
\hline & 303 & -26.0 & -14.92 & -0.037 \\
\hline \multirow[t]{3}{*}{ Gasometric } & 313 & -29.7 & -14.92 & -0.047 \\
\hline & 323 & -33.1 & -14.92 & -0.056 \\
\hline & 333 & -36.9 & -14.92 & -0.066 \\
\hline
\end{tabular}
aluminium. 
A new way to describe the entropy of the system in terms of the amount of active adsorbate molecules adsorbed onto the metal surface (i.e. degree of surface coverage) has been introduced by the authors by means of extrapolation of the Gibbs adsorption equation. Assuming the variation of degree of surface coverage with concentration of the extracts to be $\eta\left(\right.$ i.e $\delta \theta / \delta C$ ) and the moles of the active components of the extract per $\mathrm{cm}^{2}$ area of the metal surface to be $Q$ (i.e analogous to $\theta$ ), then at equilibrium, $Q$ may be related to $\eta$ by means of modifying the Gibbs adsorption equation to become equation 11 below:

$$
Q=-(C / R T) \eta
$$

where $R$ and $T$ conserve their usual meanings. When $\eta<0$, it implies that surface coverage increases with concentration (as obtained here): Q must be positive and the amount of the surface active agents is higher leading to decreased entropy (i.e Sads < 0). A plot of $\theta$ against $1 / \mathrm{T}$ (not shown) would therefore yield negative values of $\eta$ for the adsorption of $A$. boonei extract onto the aluminium surface.

2.3Kinetic/thermodynamic Characterization: Arrhenius equation (equation 11) describes the variation of corrosion rate with temperature.

$$
\log \pi=\log A-E_{a} / 2.303 R T
$$

Where $\pi$ is the corrosion rate, $T$ is the absolute temperature, $A$ is Arrhenius pre-exponential frequency factor, $R$ is the universal gas constant and $\mathrm{E} a$ is a quantity characteristic of the adsorption process with dimensions of that of energy known as activation energy and which is used to describe the kinetics of the A. boonei extracts adsorption from the Arrhenius plot of $\log \pi$ against 1/T (figure 4). Satisfactory straight lines were obtained for all the concentrations studied. The central idea here is that for the $1.0 \mathrm{M} \mathrm{H}_{2} \mathrm{SO}_{4}$ acid to attack the aluminium, its molecules must be activated over an energy barrier equals to the $\mathrm{E} a$ of the blank (table 4) and is temperature dependent. The E $a$ values obtained in the presence of the extracts are higher than that of the blank acid indicating deactivation of the acid molecules on collision with the metal surface by the introduction of the extracts thus reducing the rate of acid attack on the metal. E $a$ (inhibited) $>\mathrm{E} a$ (uninhibited) coupled with decrease in inhibition efficiency with increase in temperature have been ascribed to physical adsorption mechanism [12]. Further inspection of the E $a$ values reveals that it increases with increase in concentration of the extracts, a trend similar to that reported by other authors [13].

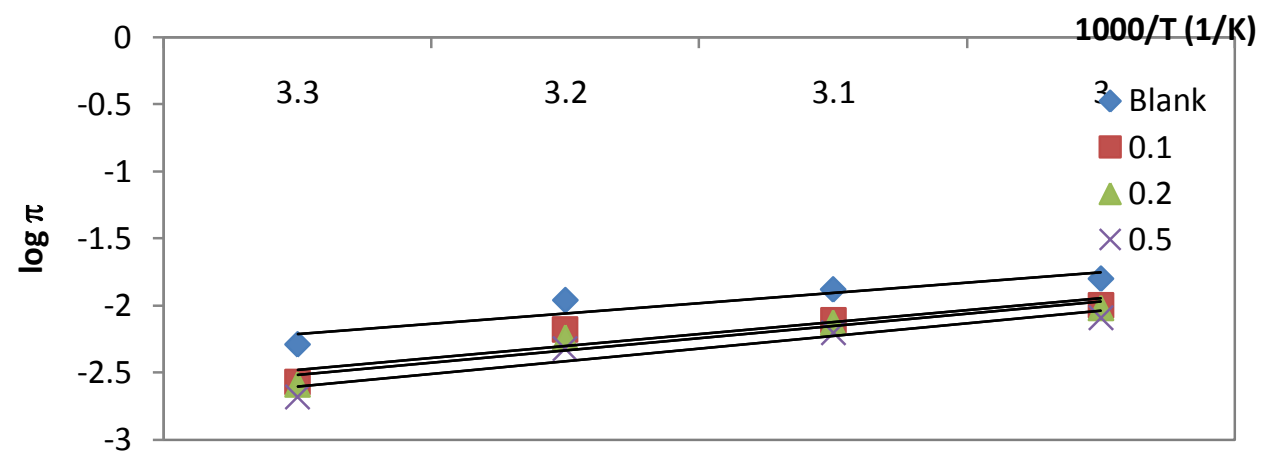

Figure 4 (a): Arrhenius plot of log $\pi$ against 1/T for the corrosion inhibition of aluminium in sulphuric acid by extract of A. boonei using weight loss measurement.

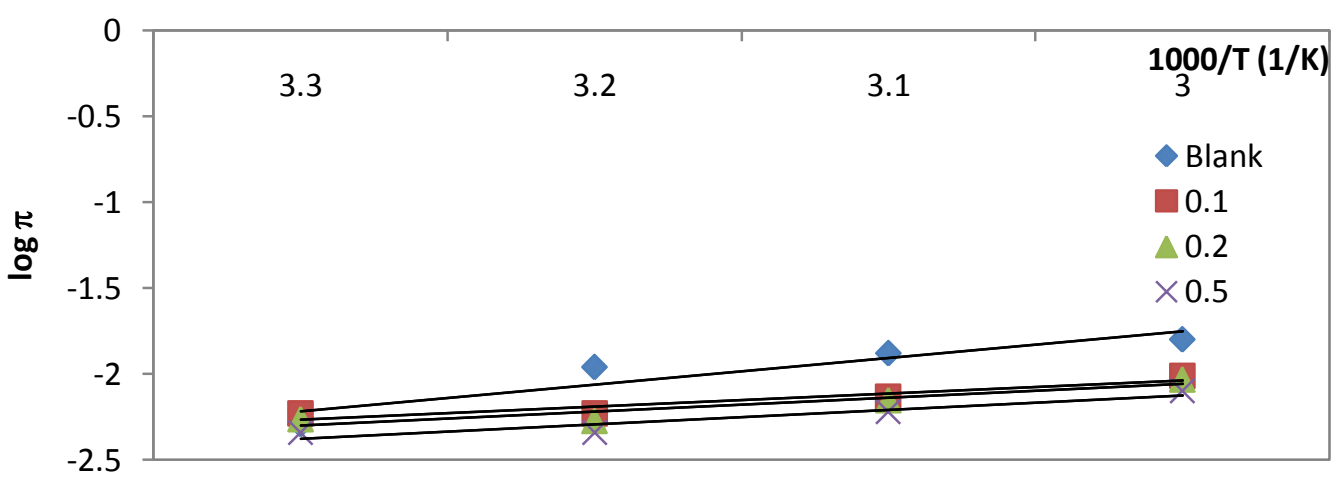

Figure 4 (b): Arrhenius plot of log $\pi$ against 1/T for the corrosion inhibition of aluminium in sulphuric acid by extract of $A$. boonei using hydrogen evolution measurement

Activation parameters were also elucidated by applying the classical thermodynamic model called the transition state equation below: 


$$
\pi=R T / N h \exp \left(\Delta S_{\mathrm{a}} / R\right) \exp \left(\Delta H_{d} / R T\right)
$$

where $N$ is the Avogadro's number and $h$ is the planks constant. $\Delta \mathrm{S} a$ and $\Delta \mathrm{H} a$ are standard change in entropy and enthalpy of activation respectively.

The enthalpy and entropy of activation are deduced from the slopes $\left(-\Delta H_{a /} 2.303 \mathrm{R}\right)$ and the intercepts $\left(\left\{\log (\mathrm{R} / \mathrm{Nh})+\left(\Delta S_{\mathrm{a}} / 2.303 \mathrm{R}\right)\right\}\right)$ of the plot of $\log (\pi / \mathrm{T})$ against $1 / \mathrm{T}$. The negative values of the $\Delta H_{a}$ indicates association dominating dissolution meaning that association of the extract with the metal surface is more significant than the metal attack, hence retardation of the dissolution process. Negative entropy of activation suggests decrease in disorderliness in the bulk solution. The values obtained are also consistent with physical adsorption mechanism. The gradual increase in negative entropy $\left(-\Delta S_{\mathrm{a}}\right)$ in the presence of the inhibitor signifies the formation of more ordered stable layer of active molecules of the extracts on the aluminium surface as extract concentration increase [14].

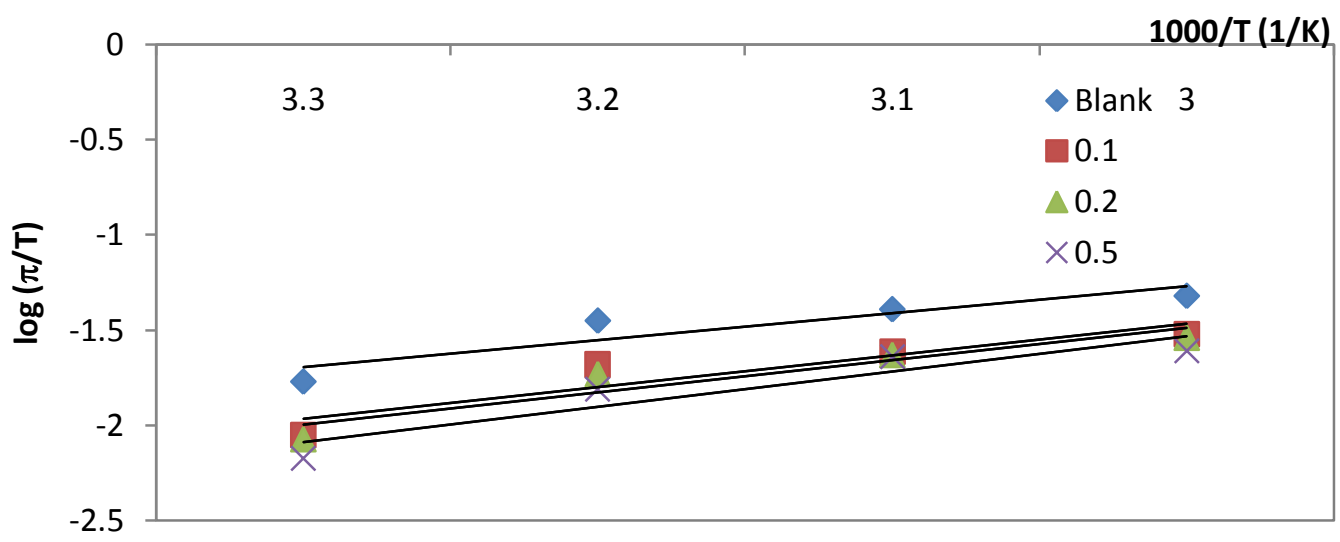

Figure 5 (a): Transition state plot of $\log (\pi / T)$ against 1/T for gravimetric measurement.

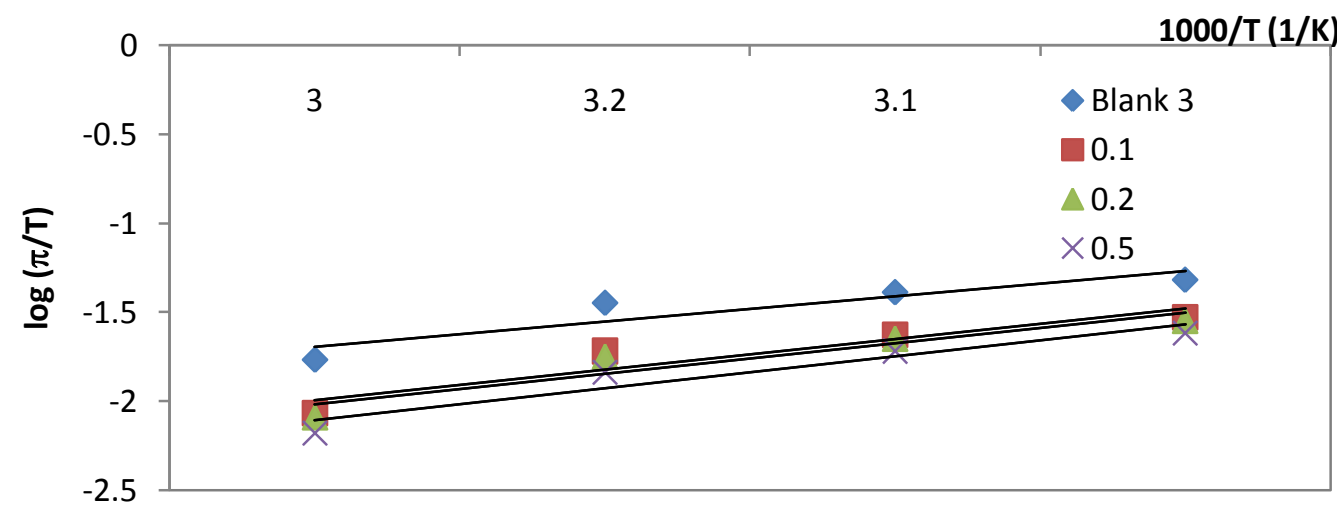

Figure 5 (b): Transition state plot of log $(\pi / T)$ against 1/T for gasometric measurement.

Table 4: Activation parameters obtained from Arrhenius and Transition state plot.

\begin{tabular}{l|lccc|cccc}
\hline \multicolumn{1}{c}{ System } & \multicolumn{5}{c|}{ Weight loss } & \multicolumn{4}{c}{ Hydrogen evolution } \\
& $\mathrm{A} \times 10^{-3}$ & $\mathrm{E} a$ & $\Delta \mathrm{H}_{a}$ & $\Delta \mathrm{S}_{a}$ & $\mathrm{~A} \times 10^{-3}$ & $\mathrm{E} a$ & $\Delta \mathrm{H}_{a}$ & $\Delta \mathrm{S}_{a}$ \\
\hline Blank & 4.27 & 2.93 & -2.70 & -23.2 & 4.27 & 1.10 & -2.70 & -23.2 \\
$0.1 \mathrm{~g} / \mathrm{L}$ & 2.19 & 3.37 & -3.17 & -23.8 & 4.57 & 1.44 & -3.27 & -23.9 \\
$0.2 \mathrm{~g} / \mathrm{L}$ & 2.00 & 3.44 & -3.23 & -23.9 & 4.17 & 1.53 & -3.29 & -24.0 \\
$0.5 \mathrm{~g} / \mathrm{L}$ & 1.60 & 3.58 & -3.54 & -24.1 & 3.31 & 1.59 & -3.44 & -24.2 \\
\hline
\end{tabular}

\section{Conclusion}

The results of this work show that the extracts of $A$. boonei appreciably retarded the dissolution of aluminium in the sulphuric acid medium.Inhibition efficiency increased with increase in concentration of the extracts but decresed with increase in temperature. The extracts inhibited the corrosion process via physical adsorption mechanism. Freundlich adsorption model best described the inhibition process. Thermodynamic parameters showed that the adsorption was spontaneous, exothermic and the entropy decreased leading to formation of ordered stable complex film on the metal surface. 


\section{References}

[1] E. E. Ebenso, N. O. Eddy, and A. O. Odiongenyi. Corrosion inhibitive properties and adsorption behaviour of ethanol extract of Piper guinensis as a green corrosion inhibitor for mild steel in $\mathrm{H}_{2} \mathrm{SO}_{4}$. African Journal of pure and Applied Chemistry, 2 (11): 2008, 107

[2] P. W. Adotey, G. E. Adukpo, Y. O. Boahen and F. A. Armah. A Review of the Ethnobotany and Pharmacological Importance of Alstonia boonei De Wild (Apocynaceae).International Scholarly Research Network (ISRN Pharmacology Volume) 2012

[3] A. C. Akinmoladun, E. O. Ibukum, ,E. Afor, T. K. Akinrinlola, , A. O. Akinboboye. E. M. Obuotor, and E. O. Farombi. Chemical Constituent and Antioxidantactivity of Altonia boonei.. African journal of Biotechnology 6 (10): 2007, 1197

[4] G. O. Oze, H. U. Nwajo, and G. O. Onyenze,. Nephrotoxicity caused by the extracts of Alstonia boonei (De Wild) in Guinea pigs. The Internet Journal of Nutrition and wellness. 3 (2): 2007,398

[5] Y. Raji, T. M. Salman and O. S Akinsomisoye. Reproductive functions in male rats treated with methanolic extracts of Alstonia boonei stem bark. African Journal of Biomedical Research 8 (2) 2005, 105

[6] S. O. Majekodunmi, O. A. Adegoke and O. A. Odeku. Formulation of extracts of the stem bark of Alstonia boonei as tablet dosage form. Journal of Pharmaceutical Research. 7 (2): 2008, 987

[7] O. A. Olajide, S. O. Awe, J. M. Makinde, A. I. Ekhelar, A. Olusola, O. Morebise and D. T. Okpako. Studies on anti-inflammatory, antipyretic and analgesic properties of Alstonia boonei stem bark .Journal of Ethnopharmacology 71 (1-2): 2000,179

[8] S. A. Umoren, I. B. Obot, E. E. Ebenso, P. C. Okafor, O. Ogbobe and E. E. Oguzie. "Gum arabic as a potential corrosion inhibitor for aluminium in alkaline medium and its adsorption characteristics", Anti-corrosion Methods and Materials, 53 (5): $2006,277-282$.

[9] S .A Umoren, and, U. F Ekanem. Inhibition of Mild Steel Corrosion in H2SO4 using Exudate Gum from Pachylobus edulis and Synergistic Potassium Halides Additives, Chemical Engineering Communications, 197 (10): 2010,1339-1356.

[10] E. E Oguzie. Corrosion inhibition of aluminium in acidic and alkaline media by Sansevieria trifasciata extract . Corrosion Science 49 (3): 2007, 1527

[11] E. B. Ituen and U. E. Udo. Phytochemical profile, adsorptive and inhibitive behavior of costus afer extracts on aluminium corrosion in hydrochloric acid. Der Chemica Sinica 3(6): 2012, 1394-1405

[12] S. P. Fakrudeen, H. B. Lokesh, H. C.AmandaMurthy and R. V. Bheema. Electrochemical investigation of corrosion inhibition of AA6063 alloy in $1 \mathrm{M} \mathrm{HCl} \mathrm{using} \mathrm{Schiff} \mathrm{base} \mathrm{compounds.} \mathrm{IOSR} \mathrm{Journal} \mathrm{of} \mathrm{Applied} \mathrm{Chemistry.} \mathrm{2(5):} \mathrm{2012,} \mathrm{37-47.}$

[13] I. B. Obot, and N O. Obi-Egbedi, 2,3-Diphenylbenzoquinoxaline: A new corrosion inhibitor for mild steel in sulphuric acid .Corrosion Science 52: 2010, 282.

[14] B. S. Prathibha, P. Kotteeswaran and V. B. Raju. Study on the inhibition of mild steel corrosion by N, N-dimethyl-N-(2phenoxyethyl)dodecan-1-aminiumbromide in HCl mediun. IOSR Journal of Applied Chemistry. Doi 10.9790/0256170 